\title{
Assessment of knowledge and practice to control nosocomial infection, among the staff nurses, hi-tech medical college and hospital
}

\begin{abstract}
A nosocomial infection is that which is acquired in a hospital or other health care agency. This study was undertaken to assess the knowledge level and practice $f$ the staff nurses to control nosocomial infection. A quantitative survey approach with nonexperimental descriptive design was undertaken for this study. The sample size was 50 and convenient sampling technique was used. Data was analyzed by using descriptive and inferential statistics. Table 1 shows the demographic characteristics of the staff nurses. Tables $2 \& 3$ reveals the association between knowledge, practice and selected demographic variables which was significant at 0.05 level.
\end{abstract}

Volume 2 Issue 2 - 2017

\author{
Ashisbala Mohapatra \\ Department of Nursing, Hi-Tech College of Nursing, India
}

Correspondence: Ashisbala Mohapatra, Department of Nursing, Hi-Tech College of Nursing, India, Tel 9937440524 Email ashisbalamohapatra@gmail.com

Received: October 20, 2016 | Published: January 25, 2017

Keywords: knowledge, practice, staff nurse, nosocomial infection

\section{Introduction}

The term "Nosocomial" is taken from the Greek word "nosocomium" meaning health care facility. A nosocomial infection is one that is acquired in a hospital or other health agency. A hospital is one of the most likely places for acquiring an infection because it harbours a high population of virulent stairs of micro-organism that are usually resistant to antibiotics. Nosocomial infections not only extend hospital care for the patient, but also increase cost for both patient and hospital. ${ }^{1}$ Nurses have an important role in preventing and controlling the nosocomial infection in the hospital. So, this study was undertaken to assess the knowledge and practice of the staff nurses.

\section{Objectives}

a. To assess the knowledge of staff nurses about nosocomial infection.

b. To assess the practice of staff nurses to control nosocomial infection

c. To associate the knowledge and practice with selected demographic variables.

\section{Hypothesis}

$\mathrm{H}_{1}$-There is significant association between level of knowledge, practice and selected demographic variables.

\section{Inclusion criteria}

i. Registered staff nurses.

ii. Nurses who are willing to participate.

\section{Theoretical framework}

Theoretical framework selected for the study is based on pender's health promotion model. In 1982, pender's health promotion in nursing practice was published with the concept of promoting optimal health superseding disease prevention. ${ }^{2}$

According to pender, the health promotion identifies cognitive perceptual factors in the individual that are modified by situational, personal and interpersonal characteristics to the result in participation of health promotion in the presence of a cue to action. In the present study, the cognitive perceptual factors are the staff nurses knowledge about control of nococomial infection in terms of importance of health and healthy behavior. ${ }^{3}$

\section{Methodology}

\section{Approach and design}

A quantitative survey approach with non-experimental descriptive design was undertaken.

\section{Setting of the study}

The study was conducted in the in-patient department of medicine wards of Hi-Tech Medical College and Hospital, Bhubaneswar.

\section{Sample and sampling technique}

The samples were the staff nurses. The sample size was 50and the convenient sampling technique was used.

\section{Research tool and technique}

The data was collected using two standardized tools. Part-A consisted of socio demographic and clinical data. Part-B consisted of questionnaire ( 25 questions) for the purpose of assessing knowledge of the staff nurses. The practice was assessed by dichotomous questions with "Yes" and "No" response. Yes carries "I" mark and No carries "O" mark.

\section{Scoring procedure}

$$
\begin{aligned}
& \text { Good } \rightarrow \text { 17-24 } \\
& \text { Average } \rightarrow \text { 9-16 } \\
& \text { Poor } \rightarrow \text { 1-8 }
\end{aligned}
$$

\section{Ethical consideration}

Before the commencement of the task of data collection, 
permission was taken from the administrative authorities. Also, permission was obtained for the sample who was willing to participate in the study. Explanation was given regarding the purpose of the study. Confidentiality was ensured. The individual participant has the right to leave the study at any time without assigning any person. ${ }^{4}$

\section{Results and discussion}

\section{Sample characteristics in frequency and percentage}

The data were collected using demographic proforma. Frequency and percentage were computed for describing the sample characteristics. Majority ( $\mathrm{n}=44,88 \%)$ staff nurses were females, $48 \%$ $(\mathrm{n}=24)$ were in the age group of 31-40 years. Majority $52 \%(\mathrm{n}=26)$ were educated up to B.Sc. $(\mathrm{N})$ and $48 \%(\mathrm{n}=24)$ were G.N.M. No one is there with M.Sc. (N) qualification Table 1.

The knowledge level was assessed by questioning and was classified as good, average and poor. The score from (17-24) was marked as good, (9-16) was average and (1-8) was poor. The percentage distribution of the staff nurses by knowledge score showed that majority $(50 \%, n-25)$ had good knowledge, $(44 \%, n=22)$ had average knowledge and $(6 \%, \mathrm{n}=3)$ had poor knowledge. ${ }^{5}$

The practice about the management of nosocomial infection was assessed by dichotomous questions with "Yes" and "No" response. The percentage distribution showed that $50 \%(\mathrm{n}=25)$ were practicing the management while educating the patients, and also attendants, for $23(46 \%)$ the management was average and $6 \%(n=03)$ were hesitant in practicing or neglecting their work due to ignorance. ${ }^{6}$

Analysis of knowledge, practice and selected demographic variables like sex, age, educational qualification shows that Tables 2 $\& 3$ reveals the association between knowledge practice and selected demographic variables which was significant at 0.05 level.

Table I Demographic characteristics of staff nurses

\begin{tabular}{llll}
\hline Variables & Characteristics & Frequency & Percentage \\
\hline \multirow{2}{*}{ Sex } & Male & 6 & 12 \\
& Female & 44 & 88 \\
& $2 I-30$ & 4 & 8 \\
Age in years & 3I-40 & 24 & 48 \\
& $4 I-50$ & 20 & 40 \\
& 5I \& above & 2 & 4 \\
Education & G.N.M & 24 & 48 \\
& B.Sc. (N) & 26 & 52 \\
& M.Sc. (N) & 0 & 0 \\
\hline
\end{tabular}

$(\mathrm{N}=50)$.

Table 2 Relationship knowledge about nosocomial infection and selected demographic variable

\begin{tabular}{|c|c|c|c|c|c|c|}
\hline Variables & Poor knowledge (I-8) & Average knowledge (9-16) & Good knowledge (17-24) & df & $\mathrm{K}^{2}$ Cal. & Table value $X^{2} 0.05$ \\
\hline \multicolumn{7}{|l|}{ Sex } \\
\hline Male & 0 & 2 & 4 & \multirow{2}{*}{\multicolumn{2}{|c|}{76.1}} & \multirow[b]{2}{*}{5.31} \\
\hline Female & 3 & 24 & 21 & & & \\
\hline \multicolumn{7}{|c|}{ Age in years } \\
\hline $21-30$ & 0 & 2 & 4 & \multirow{4}{*}{6} & \multirow{4}{*}{28.2} & \multirow{4}{*}{12.22} \\
\hline $31-40$ & I & 8 & 14 & & & \\
\hline $4 I-50$ & 2 & 11 & 6 & & & \\
\hline 51 \& above & 0 & I & 1 & & & \\
\hline \multicolumn{7}{|l|}{ Education } \\
\hline G.N.M & I & 11 & 12 & 4 & 51.7 & 9.41 \\
\hline B.Sc & 0 & 12 & 13 & & & \\
\hline
\end{tabular}

$(n=50) ;(X)$ Significant at 0.5 level

Table 3 Relationship practice of management for nosocomial infection and selected demographic variable

\begin{tabular}{lllllll}
\hline Variable & Poor (I-8) & Average (9-16) & Good (17-24) & df & $\mathbf{K}^{2}$ cal & Total value $\mathbf{X}^{2} \mathbf{0 . 0 5}$ \\
\hline Sex & 0 & 3 & 3 & & & \\
Male & 2 & 20 & 22 & 2 & 82.1 & $3.8 I$ \\
Female & 0 & 3 & & & \\
Age in years & & 8 & 5 & & & \\
$21-30$ & 0 & 10 & 9 & 6 & 36.2 & $7.5 I$ \\
$31-40$ & 1 & 9 & & & \\
$4 I-50$ & 2 & 2 & 2 & & &
\end{tabular}




\begin{tabular}{lllllll}
\hline Variable & Poor (I-8) & Average (9-16) & Good (17-24) & df & K $^{2}$ cal & Total value $\mathbf{X}^{2} \mathbf{0 . 0 5}$ \\
\hline Education & & & & & & \\
G.N.M & $\mathrm{I}$ & $\mathrm{II}$ & 12 & 4 & 14.2 & $5.8 \mathrm{I}$ \\
B.Sc.(N) & $\mathrm{I}$ & 12 & 13 & & & \\
\hline
\end{tabular}

$\mathrm{N}=50 ; \mathrm{X}$ significant at 0.05 level.

\section{Acknowledgement}

The author would like to thank the staff nurses who participated in the study without whom the study would not have been possible. Also, thanked to the Medical Superintendent and Nursing Superintendent of Hi-Tech Medial College \&Hospital, Bhubaneswar for their support and encouragement.

\section{Conflict of interest}

The author declares no conflict of interest.

\section{References}

1. Black JH, Hawks JH, Keene AM. Medical Surgical Nursing: Clinical Management for positive outcomes. 2nd ed. USA: Mosby publication; 2001. p. 512-514.
2. Smeltzer CS, Bare GB, Hinkle LJ, et al. Bruner \& Suddanth's textbook of Medical surgical Nursing. Philadelphia, USA: Lippincott wilkins and wilkiams; 2012. p. 268-270.

3. Polit DF, Beck CT. Nursing Research: Generating and assessing evidence for nursing practice. 4th ed. London, UK: Wolfer Kluwer; 2012. p. 286-288.

4. Basavanthappa BT. Nursing Theories. 2nd ed. New Delhi, India: Jaypee Brothers; 2009. p. 418-425.

5. Basavanthapa BT. Nursing Research. 2nd Ed. New Delhi, India: Jaypee Brothers; 2009. p. 576-580.

6. Gupta SP. Statistical Methods. 38th ed. New Delhi, India: Sultan Chand and Sons; 2009. 